\title{
A Modified Combined Approach Framework of Climate Impact and Adaptation Assessment for Water Resource Systems Based on Experience Derived from Different Adaptation Studies in the Context of Climate Change
}

\author{
Ganesh D. Kale \\ Research Scholar, Department of Civil Engineering, Indian Institute of Science, Bangalore, India \\ Email: kale.gd@gmail.com, samarth_ganesh2003@yahoo.com
}

Received September 22, 2013; revised October 25, 2013; accepted November 24, 2013

Copyright (C) 2013 Ganesh D. Kale. This is an open access article distributed under the Creative Commons Attribution License, which permits unrestricted use, distribution, and reproduction in any medium, provided the original work is properly cited.

\begin{abstract}
Warming of climate system is undisputed as evident from observations of increasing average temperatures of air and ocean, large scale melting of ice and increasing global average sea levels. The effect of climate change directly impacts society through the chain of climate-hydrology-water-water resources systems-society. Adaptation and mitigation are the two ways of society to respond to the changes in climate. Adaptations may be reactive, anticipatory, autonomous, planned, compliment and substitute type. The adaptations are carried out with the help of guidelines for climate impact and adaptation assessment. The guidelines are subjective or objective. Objective guidelines are step by step procedures to arrive at proper adaptation measures while subjective guidelines are step by step adaptation measures given on the basis of study of area, problem at hand and prerequisites for the adaptation. Many objective guidelines of climate impact and adaptation assessment are given. These objective guidelines can be classified into two approaches: hazard based approach and vulnerability based approach. Both approaches have their own pros and cons, so combined approach with more focus on vulnerability was suggested as the best. In this study based on the lessons learned from the adaptation case studies across the world, the combined approach framework is modified to get modified combined approach framework of guidelines for climate impact and adaptation assessment by adding the components related: 1) explicit mentioning of stakeholders 2) revision, modification and communication of adaptation actions.
\end{abstract}

Keywords: Climate Change; Adaptation; Framework of Guidelines; Climate Impact and Adaptation Assessment

\section{Introduction}

Warming of the climate system is undisputed as evident from the observations of increasing global average temperatures of air and ocean, extensive melting of snow, ice and increasing global average sea levels. Also frequency of cold days, cold nights and frost was decreasing along with the increase in the frequency of hot days and hot nights. Frequency of heavy precipitation is also found to be increased over most of the areas of the world. Thus climate change is unequivocal in the light of all aforesaid evidences. The effect of climate change has been seen almost in all sectors such as ecosystems, biological systems and hydrological systems etc. [1]. Due to increased population, industrialization and large exploitation, the water resources are under severe strain. The changes in hydrological cycle due to climate change directly impact society through the chain of climate-hydrology-waterwater resources systems-society. Thus climate change leads to an additional strain on water resources which are overstressed already.

Alterations in precipitation and temperature of the scale predicted by General Circulation Models (GCMs) for a doubled $\mathrm{CO}_{2}$ scenario were going to significantly affect the annual runoff, runoff variability and runoff seasonality. These in turn will affect the water supply, protection from floods, generation of hydropower and environmental resources. In addition the climate change is going to affect watershed's geomorphic responses, increase soil erosion and change hydrologic responses of watershed thus affecting water supply, hazard from floods and riparian systems [2].

Altered frequencies and intensities of extreme weather 
events in combination with the rise in sea level are expected to have detrimental effects on natural and human systems [1]. It is becoming more and more difficult to predict extreme weather probabilities which are fundamental for the current strategy to deal with risks and prediction of extremes based on the historical data which are not going to give any idea about the possible future extremes because of underlying uncertainties due to climate change. Thus it was suggested that socio economical systems can cope up with certain climate variability and it can minimize the ill effects of climate change [3].

The two fundamental responses of the society for minimizing the risk of climate change are mitigation and adaptation to climate change. Mitigation is minimization of causes of climate change such as minimizing greenhouse gas emissions or enhancing their sinks. However adaptations are response to the impacts of climate change for minimizing harm from climate change [4].

General definition of adaptation in the context of change in global conditions is a process, action or outcome in a system in order to better cope up, manage or adjust to some altering conditions, stress, hazard, risk or opportunity [5]. The numerous definitions of climate change can be found in the literature related to climate change. Adaptation is defined as actions targeted at the system which is vulnerable in response to actual or expected stimuli of climate with the purpose of moderating climate change harm or exploiting opportunities [4].

Also adaptation is defined as "adjustment in ecological, social, or economic systems in response to actual or expected climate stimuli and their effects or impacts" [6]. Adaptation is interpreted as response to climate change which improves the outcome [7]. Adaptation is also defined as "any adjustment whether passive, reactive or anticipatory that can respond to anticipated or actual consequences associated with climate change” [8].

Adaptations can be classified on the basis of adaptive responses such as: 1 ) reactive and anticipatory adaptation, 2) autonomous and planned adaptation, 3) substitutes and compliments. Reactive adaptation measures mean those measures which are made by institutions, individuals, animals and plants as response to climate change. Anticipatory adaptations are those measures which are carried out as preparations against potential effects of climate change. Autonomous adaptations are adjustments which are occurring naturally or spontaneously as response to climate change while planned adaptations need conscious intervention. If one adaptation measure increases the marginal benefit of other adaptation measure then it is called as complement of other while if extension of one type of adaptation measure nullifies the need of other type of adaptation measure then it is called as substitute of other adaptation [9]. We are here concerned with the reactive, anticipatory and planned adaptations.
Some other terms related to adaptation are also essential to be known like reliability, vulnerability and resiliency.

Reliability is frequency of system failure; if frequency of failure is more, reliability is less. Resiliency is the rate of recovery from failure. Vulnerability is the consequence of failure [10]. Selecting proper adaptation measures is a process which has sequences like assessment of climate change with its uncertainty, identification of component which adapts in response to climate change and selection of adaptation measures which are the most benefic [11].

Present study reviews the literature of case studies about adaptations of water resources systems to climate change across the globe and derives lessons from it. Then different approaches of objective guidelines for climate impact and adaptation assessment are discussed and the best approach out of them is found out. Finally available best approach of guidelines is modified on the basis of lessons learned from case studies about adaptations of water resource systems to climate change across the globe.

\section{Literature Review}

The studies on adaptation of water resources systems to climate change across the globe are presented chronologically. Numbers of adaptation policies for the Africa were suggested on the basis of previously carried out studies. Along with the general adaptation measures, specific adaptation measures in the sectors such as water resources, coastal resources, forests, ecosystems and agriculture were suggested for the Africa. Study suggested usefulness of incremental changes in current planning scenario for minimizing the bourdon of climate change on future generations [12].

Overview of climate change in Africa and case studies of its impacts on the water and agriculture sector were presented along with the discussion on the type of adaptation measures most effective for different stakeholders of society. The most effective strategies were presented like reduction of the present vulnerability, enhancing the broad spectrum of capacity in response to environmental, economic and resource perturbations. Systematic evaluation of priorities and constraints along with the involvement of stakeholders was suggested necessary for process of planning of adaptation strategies [13].

The study on potential impacts of climate change on hydrology and water resources of four basins in Czech Republic was carried out through the chain of water balance model/conceptual model-general Circulation Model (GCMs) generated scenarios/incremental scenarios-downscaling-rainfall-hydrological models-runoff. Results of the study shown that decreasing trend of rainfall will cause ground water decrease and consequently critical condition of long term drought in future. The study recommended giving preference to adoption of nonstruc- 
tural measures of adaptation such as conservation of water, efficient management of water demand and water resources protection [14].

Some of the elements which characterize an efficient strategy to adapt to climate change were discussed. Such strategy has to account long time horizon and prevailing uncertainties in assessment of climate change. The intuitively best approach was suggested such as enhancement of resilience and flexibility of system to react to and cope with climate shocks and extremes, as well as improvement of information. Also increasing robustness of structures or increasing the rate of depreciation for allowing earlier replacement were suggested for quasi irreversible investment with long life time [9].

Economic theory of endogenous risk was used for addressing optimal mix of mitigation and adaptation strategies along with the study of how this optimal mix get affected by adverse effect of increased variability of climate in climate change. Study argued that the better understanding the linkage between the adaptation and mitigation can provide more risk reduction with less expenditure. The policy framed by neglecting these links can undermine the effectiveness of public sector programs and policies due to unaddressed conflicts between strategies [15].

Importance of efficient adaptation was discussed. Different aspects of private and joint adaptation were presented and compared. Study revealed need of government to think about joint adaptation with being careful to design efficient responses which will treat problems related to climate change as soon as they appear. Thus through the dynamic policies and adaptation costs, remaining impacts of climate change can be decreased substantially [16].

Nature of risk and vulnerability in the context of climate change was studied along with the review of adaptations carried out in developing countries and co-ordinated international action on adaptations in future. The populations at risk were ranging from owners of second home beach front properties in North America and Europe to laborers and farmers in Africa and Asia. Study shown importance of consideration of right to development and security in building adaptive capacity rather than avoidance of pertinent risks [17].

Perspectives on collective action for natural resource management for informing understanding of climate response capacity were reviewed. For this purpose, study of collective action for community based management of coastal area in Trinidad and Tobago was carried out. Case study shown that community based management enhances adaptive capacity in two ways: by forming networks essential for coping with the extreme events and by holding back the resilience of supporting resources and ecological systems [18].
Concept of adaptation of human communities to change in climate specifically in the context of adaptive capacity and vulnerability was reviewed. The study mainly focused on the scholarship which was required to carry out adaptations at community level. The study reported the usefulness of vulnerability indices for providing the useful information regarding the relative vulnerability scores at different levels such as country, region and community. Also study suggested that the mostly adaptation measures were integrated or mainstreamed in to other programs such as resource management, preparedness for disaster and sustainable development [5].

California's water supply system ability to adapt to long term climatic and demographic shifts was examined. Two climate warming scenarios and one historical climate scenario along with population and land use estimates for the year 2100 were used in the study. Population and land use for year 2100 were estimated by application of statewide economic engineering optimization model of water supply management. Study shown that California's water supply system was physically able for adapting to the significant alterations in climate and population but by taking significant cost. Results of the study shown importance of considering some aspects such as other significant changes expected during long term time frame, allowing the system to adapt to alterations in conditions, system representation in sufficient operational and hydrologic detail and breadth for allowing the significant adaptation [19].

An assessment framework for identification of robust adaptation strategies for responding to climate change uncertainties was presented. The framework was applied to a case study of management of water resources in East of England. Study concluded that clear robust adaptation decisions are desirable but they should be negotiated between decision makers and stakeholders involved in the process of adaptation [20].

Wide literature on the subject of uncertainties in assessment of climate change and climate change adaptation was reviewed. It was found that different attitudes towards the risks and uncertainty lead to different frameworks of decision making. The different decision frameworks and tools of uncertainty analysis were grouped in three approaches: top down approach, bottom up approach and mixed approach. For top down approaches strategies were prevention principle, IPCC approach and risk approach. For bottom up approaches strategies were; precautionary principle, engineering safety margin, anticipating design, resilience and adaptive management. For mixed and alternative approaches the strategies were; approaches of human development, framework of adaptation policy and robust decision making. Study argued the application of both top down and bottom up approaches and selecting the one which performs better [21]. 
Current thinking about the planned adaptations was summarized in the study [4]. Key concepts of adaptation, description of adaptation context diversity, discussion of key prerequisites for effective adaptation were described in the study. Also major approaches to impact of climate, assessment of adaptation and their evolution were reviewed. Principles for adaptation assessment were deduced from decision analytical considerations and past adaptation assessments experiences. These principles were as given below.

- Larger the importance of climatic factor in decision making and larger the risk associated with climate change then there is need of detailed assessment of risks associated with change in climate.

- Better the knowledge about changes in future climatic risks more specific action is possible in current scenario.

- Less the experience in managing a specific risk, then greater is the need of new and additional action.

- Addressing current climate risk along with the future climate change is usually beneficial specifically when current risks are large, for most effective and efficient strategy of adaptation.

- If low regret or no regret options available, planned adaptation does not necessarily rely on projections of reliable climate impact.

New discourse of adaptation was addressed with the argument that process of adaptation so far focused on responding to climate change impacts instead of addressing underlying causes of vulnerability. Study argued that putting the adaptation in better place in development planning is like to put the cart before the horse. So addressing the causes of vulnerability is the actual role the development has to play for making adaptation process successful [22].

Incorporation of climate change research in to planning and management tools by the agencies managing California's water resources through the chain of GCMsscenarios-downscaling-temperature, rainfall etc.-rainfallhydrological models-runoff was presented in the study. Study shown greater amounts of winter season runoff combined with decreased spring season runoff. Both impacts were found to pose challenges for maintaining State Water Projects and Federal Central Valley Project performance levels as prevailing at the time of study. So study argued that risk assessment should involve potential scenarios spectrum, impacts of each scenario and relative probability estimates for each scenario [23].

Report presented a quick overview of effects of climate change and adaptation measures already carried out in Belgium. Adaptation measures were not only focused on defending against the climate change threats but also on finding new possibilities and capitalizing favorable changes in climate. Study shown that extensive linkage between different adaptation efforts and their corresponding policy areas could lead to synergies and would help in avoiding the maladaptation [24].

Guidance regarding the adaptation to climate change in cities was provided. It was suggested that addressing of basic poverty reduction issues and sustainable development goals can increase the resilience of cities. So cities can mainstream the resilience into the existing efforts. Integration of disaster risk reduction (DRR) of cities with climate change considerations was also suggested. Simple and low cost measures suggested for increasing resilience in day to day operations. Collaborative problem solving and coordination across all sectors was suggested for the climate change adaptation in cities [25].

It was suggested that methods of risk management in water resources have been used in USA and elsewhere in the context of highly developed sets of criteria of planning. These risk management methods were classified as methods to assess risk and to manage the risk. The robustness and resiliency of the existing risk management methods in water planning have potential to serve as basis for adaptations to alterations in supply and demand of water caused due to climate change. While considering the climate change effect as an external variable in applications, the planners should know the information about; monitoring of climate related factors of concern, the conditions related to prospect of climate change, best ways of adapting to uncertainties and possible climate change impacts [26].

The report draws upon findings and discussions arising from Water Service Association of Australia (WSAA) climate change adaptation workshop. Report consists of three key themes and within each theme; risks, key challenges were identified as adaptation actions were already started. The report concluded that strategy development; approaches of planning, new augmentations and large focus on the interconnectivity, collaboration have all been used as tools of change. Also study concluded that implementing adaptation measures in response to the climate change, the actions should be regularly reviewed and modified and communicated as per necessity [27].

Adaptation at local scale and long run capacity building in acequia communities in Northern New Mexico was studied. Survey approach was used to identify factors and community characteristics contributed to community adaptation, level and extent of preparedness of community, preferred actions of community to withstand stresses and disturbances. Study found need of; examining adaptation and adaptive capacity building within rural communities and at local scale, activities of community strengthening, co-operation building within and between communities. Maintaining and strengthening of rural extension programs, activities for integration of new methods and techniques within existing system of community culture were recommended by the study [28]. 
Self assessment survey and workshop were used to provide perspective of planner knowledge about adaptation to climate change along with study of impacts of climate in communities across the province of British Columbia, Canada and obstacles to effective adaptation. The results of the study indicated that planners do not have high level knowledge about adaptation to climate change. Study found the need of promoting capacity building relevant to adaptation to climate change among planners. Planning institutes and academics, governments at local, regional, provincial, federal levels etc. should utilize and built upon existing resources to enhance the knowledge of planners about the adaptation to climate change [29].

A range of case studies were presented, illustrating Low Impact Development (LID) advantages in monetary terms and metrics employed in decision making at municipal level. Also it was stated that Green Infrastructure (GI) individually has additional upfront capital expenditure to a project but it can result in reduced need of capital investment for conventional drainage structures. LID as measure of adaptation can increase the onsite runoff storage compensating for increases in depths of rainfall due to climate change. The other benefit of LID found was; increase in resiliency by increasing lag time, reducing and delaying peak discharge of runoff [30].

Extent of adaptation integrated in to Dutch local policies and the role of municipality's size, risk and experience in encountered adaptation manifestations was examined in the study. Firstly study found that anticipatory adaptations were took place only for perceivable weather extremes like increasing precipitation. Secondly it was found that realization of further adaptations was hindered by the reality of strong sectoral divide. Also adaptations were found to be mainly dominated by water department and other departments like spatial planning and environment were involved limitedly. Study suggested tackling of sectoral divides by administrative efforts like professional training carried out in vertical direction [31].

The influence of formal education in adaptive capacity determination of residents of two low income settlements: Los Manantiales in San Salvador, El Salvador and Rocinha in Rio de Janeiro, Brazil were examined. The study was carried out on the basis of qualitative and quantitative analysis of collected data. Quantitative analysis was carried out with the help of correlation. It was found that, in both the case studies the average level of education was lower for households which were living at higher risk as compared to residents of lower risk areas. Study strongly argued promotion of formal education for increasing the adaptive capacity of people [32].

Differences in institutional and local responses to change in climate and disasters were analyzed in a Southern and a Northern city. San Salvador, En Salvador in Central America was the Southern city while Manchester,
United Kingdom was the Northern city. Study found that in South, local coping strategies were an important element of climate change adaptation and disaster risk adaptation because of limited help provided by urban actors, associated social security and systems of governance. In North, the local coping strategies were poorly developed due to dominant role of Northern institutions. Study suggested the transformation of lessons learned in to the improved distributed governance system. The improved distributed governance system is an integrated engagement model in which local and institutionalized responses support each other [33].

Study focused on the issues of impacts of climate change and vulnerability assessment of agriculture sector of India. Range of adaptation strategies were suggested for improvement of agricultural management in view of climate change for sustainable development leading to pathways of climate resiliency. Risk management and strategies of vulnerability reduction were found to be two ways of becoming more climate resilient on the pathways of sustainable development [34].

The lessons learned from the above case studies are summarized below.

- Incremental changes in current planning scenario for minimizing the bourdon of climate change on future generations.

- Systematic evaluation of priorities and constraints along with the involvement of stakeholders for process of planning of adaptation strategies.

- Giving preference to adoption of nonstructural measures of adaptation.

- Enhancement of resilience and flexibility of system.

- Understanding the linkage between the adaptation and mitigation.

- Joint adaptation with being careful to design efficient responses to climate change.

- Consideration of right to development and security in building adaptive capacity.

- Community based management enhances adaptive capacity.

- Usefulness of vulnerability indices for providing the useful information regarding the relative vulnerability scores at different levels.

- Consideration of some aspects such as other significant changes expected during long term time frame, system representation in sufficient operational and hydrologic detail.

- Negotiation between decision makers and stakeholders involved in the process of adaptation.

- Application of both top down and bottom up approaches for adaptation assessment and selecting the best one.

- Addressing current climate risk along with the future climate change. 
- If low regret or no regret options available, planned adaptation does not necessarily rely on projections of reliable climate impact.

- Addressing the causes of vulnerability is the actual role of development.

- Risk assessment should involve potential scenario spectrum, impacts of each scenario and relative probability estimates for each scenario.

- Extensive linkage between different adaptation efforts and their corresponding policy areas could lead to synergies.

- Simple and low cost measures for increasing resilience in day to day operations should be adopted.

- The robustness and resiliency of the existing risk management methods in water planning have potential to serve as basis for adaptation.

- Planners should know the information about; monitoring of climate related factors of concern, the conditions related to prospect of climate change, best ways of adapting to uncertainties and possible climate change impacts.

- Implementing adaptation measures in response to the climate change, the actions should be regularly reviewed and modified and communicated as per necessity.

- Maintaining and strengthening of rural extension programs, activities for integration of new methods and techniques within existing system of community culture.

- Enhancing the knowledge of planners about the adaptation to climate change.

- Use of Low Impact Development and Green Infrastructure for adaptation.

- Tackling of sectoral divides by administrative efforts like professional training.

- Promotion of formal education for increasing the adaptive capacity of people.

- Local and institutionalized responses should support each other.

- Risk management and strategies of vulnerability reduction should be adopted.

\section{Methodology}

Climate impact and adaptation assessment guidelines are those based on which the entire procedure of selecting proper adaptation is performed. The guidelines can be subjective means step by step adaptation measures derived on the basis of study of conditions of particular area, problem at hand and prerequisites of adaptation (prerequisites of adaptation were discussed in [4]). Several subjective guidelines on different sectors and regions are given ([21,31, $35-40])$. Objective guidelines are nothing but the step by step procedure to arrive at proper adaptation process and these are general guidelines.

Different objective guidelines of climate impact and adaptation assessment are given in the IPCC Technical Guidelines, the USCSP International Handbook, the UNEP Handbook, Climate Change Adaptation through Integrated Risk Assessment Guidelines and the UNDPGEF Adaptation Policy Framework ([4] and reference therein).

Hazard based approach and vulnerability based approach are the two approaches applied in guidelines for climate impact and adaptation assessment. Hazard based approach gives more emphasis on the climate change incremental impacts. In hazard based approach the assessment begins with the projections of climate change by different climate models. Several reviews have concluded that these hazard based assessments are important for identification of climate change risks but its results are not useful immediately for design of adaptation policy. USCSP Guidebook and UNEP Handbook have used this approach. Important shortcomings of hazard based approach are: over reliance on the model based climate, non availability of climate impact projections at spatial scales required by the decision makers, long term climatic projections which have less relevance to many adaptation actors and less emphasis on non climatic factors, natural variability of climate. On the other hand vulnerability based approach assesses future climate change in the light of current climatic risks with strong emphasis on the social factors which determine ability to cope up with hazards from changing climate. This approach begins with the past experiences of managing risks of climate, involves all the stakeholders from beginning and links the adaptation to climate change with the activities of stakeholders directly. If low or no regret options of adaptation are available then this approach can produce useful results without considering reliable impact projections. Disadvantages of vulnerability approach are: greater importance given to expert judgment, comparability across the regions is limited because of large qualitative natured results and absence of clear methodology. This approach was used in the UNDP-GEF adaptation policy framework. The initial emphasis on the hazard based approach was evolved towards integration of both approaches with more focus on the vulnerability approach [4]. The combined approach presented in [4] is shown in Figure 1.

This approach gives more comprehensive picture of current and future climate risks by considering future climate change with current variability of climate and non climatic factors. In this combined approach, risk assessment is based on experience of managing past climate hazards and recommendations for adaptations were based on the view of reducing current and future climate risks. Also the recommendations were decided on the basis of the synergy with other policy objectives such as goals of 


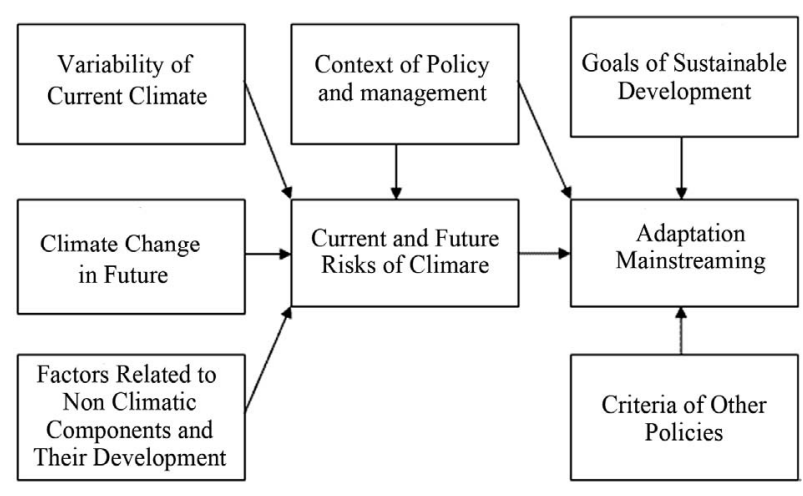

Figure 1. Combined approach of climate impact and adaptation assessment (Source: [4]).

sustainable development in addition to their potential to reduce current and future risks due to climate change. Consideration of wider adaptation policy context lead to suggestions about mainstreaming of adaptations to climate change into existing activities of management and plans of development. This more inclusive approach to assessment of adaptation and planning of adaptation was recommended in frameworks like UNDP-GEF Adaptation Policy Framework [4]. This approach has been used by many adaptation projects across the globe like Mainstreaming Adaptation to Climate Change project carried out by World Bank and Asian Development Bank administered project "Climate Change Adaptation Program for the Pacific" ([4] and reference there in).

Based on the lessons learned from the case studies of the adaptation to climate change across the globe, following aspects are recommended to be considered in the policy and management context of above combined framework.

\section{Policy and Management Context}

- Incremental changes in current planning scenario for minimizing the bourdon of climate change on future generations.

- Systematic evaluation of priorities and constraints along with the involvement of stakeholders for process of planning of adaptation strategies.

- Giving preference to adoption of nonstructural measures of adaptation.

- Enhancement of resilience and flexibility of system.

- Understanding the linkage between the adaptation and mitigation.

- Joint adaptation with being careful to design efficient responses to climate change.

- Community based management for enhancement of adaptive capacity.

- Consideration of vulnerability indices for providing the useful information regarding the relative vulnerability scores at different levels.
- Consideration of some aspects in adaptation assessment such as other significant changes expected during long term time frame, system representation in sufficient operational and hydrologic detail.

- Negotiation between decision makers and stakeholders involved in the process of adaptation.

- Risk assessment should involve potential scenario spectrum, impacts of each scenario and relative probability estimates for each scenario.

- Simple and low cost measures for increasing resilience in day to day operations.

- Increasing robustness and resiliency of the existing risk management methods in water planning.

- Planners should know the information about; monitoring of climate related factors of concern, the conditions related to prospect of climate change, best ways of adapting to uncertainties and possible climate change impacts.

- Maintaining and strengthening of rural extension programs, activities for integration of new methods and techniques within existing system of community culture.

- Enhancing the knowledge of planners about the adaptation to climate change.

- Use of Low Impact Development and Green Infrastructure for adaptation.

- Tackling of sectoral divides by administrative efforts like professional training.

- Promotion of formal education for increasing the adaptive capacity of people.

- Local and institutionalized responses should support each other.

- Risk management and strategies of vulnerability reduction should be adopted.

- System representation in sufficient operational and hydrologic detail.

As the adaptation process needs all stakeholders' contribution to the process, the involvement of stakeholders in decision making is important and it is in implicit form in combined framework but it should be explicitly shown. As the climatic, non climatic factors are dynamic in nature, the actions performed for the implementation of adaptations should be regularly revised, modified and communicated to the concerned stakeholders. So involvement of stakeholders in decision making and revision, modification and communication of adaptation actions to concerned stakeholders are very important aspects and they are added in the combined approach framework given in [4] to derive modified combined approach framework of climate impact and adaptation assessment as presented in Figure 2.

Thus modified combined approach framework of climate impact and adaptation assessment will be more useful than the earlier framework. 


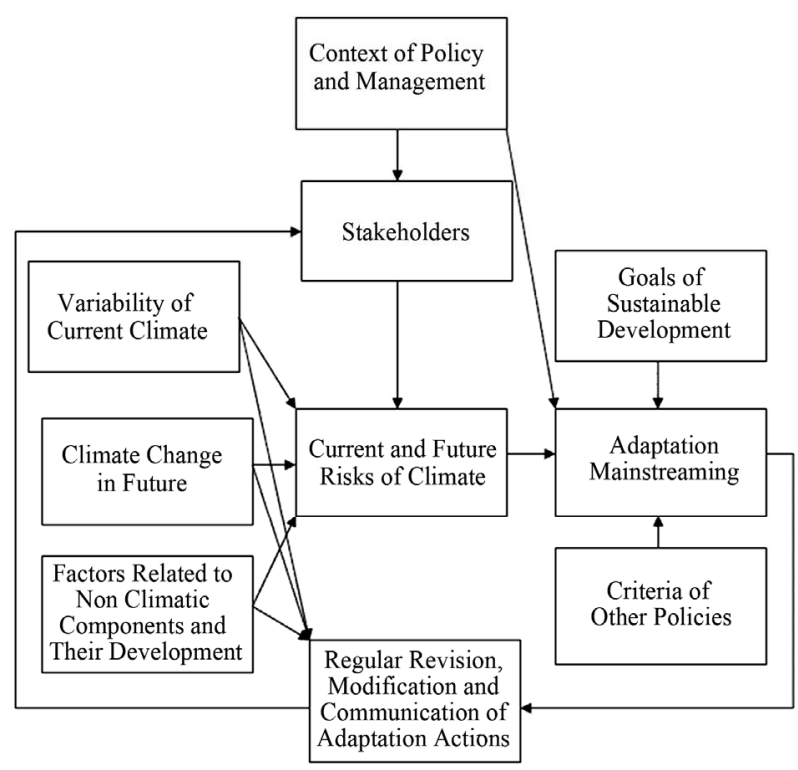

Figure 2. Modified framework of climate impact and adaptation assessment.

\section{Conclusion}

The objective guidelines for adaptation planning and management are the basis for carrying out adaptation measures across the world. The objective guidelines have two approaches: hazard based approach and vulnerability based approach. But combined approach of these two with more emphasis on vulnerability approach was suggested to be the best [4]. So modifying this combined approach framework of objective guidelines on the basis of policy implications derived from different case studies will help in overall improvement of adaptation process. So this combined approach framework is modified to get modified combined approach framework of guidelines for climate impact and adaptation assessment by adding the components related to: 1) explicit mentioning of stakeholders 2) revision, modification and communication of adaptation actions to relevant stakeholders. This modified framework will be useful in improving overall procedure of climate impact and adaptation assessment.

\section{REFERENCES}

[1] IPCC, “Climate Change 2007: Synthesis Report, Summary for Policymakers," Intergovernmental Panel on Climate Change, Valencia, 2007, p. 22.

[2] P. Williams, "Adapting Water Resources Management to Global Climate Change,” Climatic Change, Kluwer Academic Publishers, Vol. 15, 1989, pp. 83-93.

[3] C. Pahl-Wostl, "Transitions towards Adaptive Management of Water Facing Climate and Global Change,” Water Resources Management, Vol. 21, 2007, pp. 49-62. http://dx.doi.org/10.1007/s11269-006-9040-4

[4] H. M. Fussel, “Adaptation Planning for Climate Change:
Concepts, Assessment Approaches, and Key Lessons," Sustain Science, Vol. 2, No. 2, 2007, pp. 265-275. http://dx.doi.org/10.1007/s11625-007-0032-y

[5] B. Smit and J. Wandel, “Adaptation, Adaptive Capacity and Vulnerability," Global Environmental Change, Vol. 16, 2006, pp. 282-292.

http://dx.doi.org/10.1016/j.gloenvcha.2006.03.008

[6] IPCC, "Climate Change 2001: Impacts, Adaptation, and Vulnerability,” Intergovernmental Panel on Climate Change, Cambridge University Press, Cambridge, 2001.

[7] J. Reilly and D. Schimmelpfennig, "Portraits of Adaptation to Long Term Climate Change,” Climatic Change, Kluwer Academic Publishers, Vol. 45, 2000, pp. 253-278.

[8] T. R. Carter, M. L. Parry, H. Harasawa and S. Nishioka, "IPCC Technical Guidelines for Assessing Climate Change Impacts and Adaptations,” Intergovernmental Panel on Climate Change, 1994.

[9] S. Fankhauser, J. B. Smith and R. S. J. Tol, "Weathering Climate Change: Some Simple Rules to Guide Adaptation Decisions," Ecological Economics, Vol. 30, 1999, pp. 6778. http://dx.doi.org/10.1016/S0921-8009(98)00117-7

[10] W. E. Riebsame, “Adjusting Water Resources Management to Climate Change," Climatic Change, Kluwer Academic Publishers, Netherlands, Vol. 13, 1988, pp. 69-97.

[11] B. Smit, I. Burton, R. J. T. Klein and R. Street, "The Science of Adaptation: A Framework For Assessment,” Mitigation and Adaptation Strategies for Global Change, Kluwer Academic Publishers, Vol. 4, 1999, pp. 199-213.

[12] J. B. Smith and S. S. Lenhart, "Climate Change Adaptation Policy Options,” Climate Research, Vol. 6, 1996, pp. 193-201. http://dx.doi.org/10.3354/cr006193

[13] T. E. Downing, L. Ringius, M. Hulme and D. Waughray, "Adapting to Climate Change in Africa," Mitigation and Adaptation Strategies for Global Change, Kluwer Academic Publishers, Vol. 2, 1997, pp. 19-44.

[14] V. Dvorak, J. Hladny and L. Kasparek, “Climate Change Hydrology and Water Resources Impact and Adaptation for Selected River Basins in the Czech Republic," Climatic Change, Kluwer Academic Publishers, Vol. 36, 1997, pp. 93-106.

[15] S. Kane and J. F. Shogren, "Linking Adaptation and Mitigation in Climate Change Policy," Climatic Change, Kluwer Academic Publishers, Vol. 45, 2000, pp.75-102.

[16] R. Mendelsohn, "Efficient Adaptation to Climate Change," Climatic Change, Kluwer Academic Publishers, Vol. 45, 2000, pp. 583-600.

[17] W. N. Adger, S. Huq, K. Brown, D. Conway and M. Hulme, "Adaptation to Climate Change in the Developing World,” Progress in Development Studies, Vol. 3, No. 179, 2003. http://dx.doi.org/10.1191/1464993403ps060oa

[18] E. L. Tompkins and W. N. Adger, "Does the Adaptive Management of Natural Resources Enhance Resilience to Climate Change?” Ecology and Society, Vol. 9, No. 2, 2004. http://www.ecologyandsociety.org/vol9/iss2/art10/

[19] S. K. Tanaka, T. Zhu, J. R. Lund, R. E. Howitt, M. W. Jenkins, M. A. Pulido, M. Tauber, R. S. Ritzema and R. C. Ferreira, "Climate Warming and Water Management Adaptation for California,” Climatic Change, Kluwer Acade- 
mic Publishers, Vol. 76, 2006, pp. 361-387.

[20] S. Dessai and M. Hulme, “Assessing the Robustness of Adaptation Decisions to Climate Change Uncertainties: A Case Study on Water Resources Management in the East of England,” Global Environmental Change, Vol. 7, 2007, pp. 59-72.

http://dx.doi.org/10.1016/j.gloenvcha.2006.11.005

[21] S. Dessai and J. V. D. Slujis, "Report NWS-E-2007-198," Report Prepared for Netherlands Environmental Assessment Agency, 2007.

[22] E. L. F. Schipper, "Climate Change Adaptation and Development: Exploring the Linkages,” Working Paper 107, Tyndall Centre for Climate Change Research, 2007. http://www.preventionweb.net/files/7782_twp107.pdf

[23] J. Anderson, F. Chung, M. Anderson, L. Brekke, D. Easton, M. Ejeta, R. Peterson and R. Snyder, "Progress on Incorporating Climate Change into Management of California's Water Resources," Climatic Change, Vol. 87, No. S1, 2008, pp. S91-S108. http://dx.doi.org/10.1007/s10584-007-9353-1

[24] National Climate Commission, Belgium, "Belgium National Climate Change Adaptation Strategy,” Report of National Climate Commission, 2010.

http://airclimat.wallonie.be/spip/IMG/pdf_Belgian_Natio nal_Adaptation_Strategy.pdf

[25] The World Bank Group, "Guide to Climate Change Adaptation in Cities,” 2011, p. 99.

http://iaibr3.iai.int/twiki/pub/ForoEditorial2012/WebHom e/Urban_Handbook_Final.pdf

[26] D. C. Major, "Climate Change and Water Resources: The Role of Risk Management Methods,” Journal of Contemporary Water Research and Education, Vol. 112, No. 1, 2011, pp. 47-50.

[27] Water Services Association of Australia, "Climate Change Adaptation and the Australian Urban Water Industry," Occasional Paper 27, 2012.

https://www.wsaa.asn.au/WSAAPublications/Occasional \%20Papers/Climate\%20Change\%20Adaptation\%20and\% 20the\%20Australian\%20Water\%20Industry.pdf

[28] L. Mayagoitia, B. Hurd, J. Rivera and S. Guldan, "Rural Community Perspectives on Preparedness and Adaptation to Climate-Change and Demographic Pressure," Journal of Contemporary Water Research and Education, Universities Council on Water Resources, No. 147, 2012, pp. 49-62. http://dx.doi.org/10.1111/j.1936-704X.2012.03102.x

[29] I. M. Picketts, J. Curry and E. Rapaport, "Community Adaptation to Climate Change: Environmental Planners' Knowledge and Experiences in British Columbia, Canada," Journal of Environmental Policy and Planning, Vol. 14, No. 2, 2012, pp. 119-137. http://dx.doi.org/10.1080/1523908X.2012.659847

[30] R. M. Rossen, T. V. Janeski, M. Simpson, J. J. Houle, J.
Gunderson and T. P. Ballestero, "Economic and Adaptation Benefits of Low Impact Development,” Proceedings of Low Impact Development Symposium, Asheville, North Carolina, 2012, pp. 1-20.

[31] M. V. D. Berg, and F. Coenen, "Integrating Climate Change Adaptation into Local Policies and the Role of Contextual Factors,” Local Environment, Vol. 17, No. 4, 2012, pp. $441-460$ http://dx.doi.org/10.1080/13549839.2012.678313

[32] C. Wamsler, "Climate Change Adaptation and Formal Education: The Role of Schooling for Increasing Society's Adaptive Capacities in El Salvador and Brazil," Ecology and Society, Vol. 17, No. 2, 2012. http://dx.doi.org/10.5751/ES-04645-170202

[33] C. Wamsler, “Complementing Institutional with Localised Strategies for Climate Change Adaptation: A South North Comparison,” Disasters, Vol. 36, No. 1, 2012, pp. 28-53.

http://dx.doi.org/10.1111/j.1467-7717.2011.01248.x

[34] A. Khajuria and N. H. Ravindranath, "Climate Change in Context of Indian Agricultural Sector," Journal of Earth Science and Climatic Change, Vol. 3, No.1, 2012, p. 110. http://dx.doi.org/10.4172/2157-7617.1000110

[35] R. Swart, R. Biesbroek, S. Binnerup, T. R. Carter, C. Cowan, T. Henrichs, S. Loquen, H. Mela, M. Morecraft, M. Reese and D. Rey, "Europe Adapts to Climate Change: Comparing National Adaptation Strategies,” PEER Report No. 1, Helsinki: Partnership for European Environmental Research, 2009.

[36] A. K. Gain, C. Giupponi and F. G. Renaud, "Climate Change Adaptation and Vulnerability Assessment of Water Resources Systems in Developing Countries: A Generalized Framework and a Feasibility Study in Bangladesh," Water, Vol. 4, 2012, pp. 345-366. http://dx.doi.org/10.3390/w4020345

[37] K. Kopke and C. O’Mahony, "Preparedness of Key Coastal and Marine Sectors in Ireland to Adapt to Climate Change,” Marine Policy, Vol. 35, 2011, pp. 800-809. http://dx.doi.org/10.1016/j.marpol.2011.01.008

[38] A. Kerr and A. McLeod, "Potential Adaptation Strategies for Climate Change in Scotland,” Technical Report, Scottish Executive Central Research Unit, 2001.

[39] N. S. Pradhan, V. R. Khadgi, L. Schipper, N. Kaur, T. Geoghegan and Editors, "Role of Policy and Institutions in Local Adaptation to Climate Change: Case Studies on Responses to Too Much and Too Little Water in the Hindu Kush Himalayas,” International Centre for Integrated Mountain Development Publication, 2012, 74 p.

[40] S. Ghosh, D. Raje and P. P. Mujumdar, "Mahanadi Stream Flow: Climate Change Impact Assessment and Adaptive Strategies,” Current Science, Vol. 98, No. 8, 2010, pp. 1084-1091. 